\title{
Analysis of propagation delays of compressional Pi 2 waves between geosynchronous altitude and low latitudes
}

\author{
Shun Imajo ${ }^{\text {* }}$, Kiyohumi Yumoto ${ }^{1,2}$, Teiji Uozumi², Hideaki Kawano ${ }^{1,2}$, Shuji Abe ${ }^{2}$, Akihiro Ikeda ${ }^{3}$, \\ Kiyokazu Koga ${ }^{4}$, Haruhisa Matsumoto ${ }^{4}$, Takahiro Obara ${ }^{5}$, Richard Marshall ${ }^{6}$, Victor A Akulichev ${ }^{7}$, \\ Ayman Mahrous ${ }^{8}$, Adam Liedloff ${ }^{9}$ and Akimasa Yoshikawa ${ }^{1,2}$
}

\begin{abstract}
The propagation of compressional Pi 2 waves in the inner magnetosphere is investigated by analyzing the onset delay times between the ground and the geosynchronous altitude. We use the compressional component (northward) of magnetic data from low-latitude stations and the geosynchronous satellite ETS-VIII (GMLat. $=-10.8^{\circ}$, GMLon. $=$ $217.5^{\circ}$. The onset delays are determined by a cross-correlation analysis, and we analyzed the events with high waveform correlations (correlation coefficient greater than 0.75 ). Some of these high-correlation events have the properties of propagating waves; Pi 2 waveforms at the ground stations and the satellite were synchronized with each other when the data were shifted by onset delays. The results of the statistical analysis show that $87 \%$ of the Pi 2 onsets at a ground station (Kuju, GMLat. $=26.13^{\circ}$, GMLon. $=202.96^{\circ}$ ) were delayed from the Pi 2 onsets at ETS-VIII, and the average of the delay times was $29 \mathrm{sec}$. This clearly shows Pi 2 onsets (initial perturbations of Pi 2) propagated from the geosynchronous altitude to the low-latitude ground. The delay times tended to be larger around the midnight sector than around the dawn and dusk sectors. These results are consistent with two-dimensional propagation of fast waves estimated by the model of Uozumi et al. (J Geophys Res 114:A11207, 2009). The delay times are nearly identical to the travel time of fast waves from geosynchronous altitude to the low-latitude ground, and the local time variation of the delay shows the azimuthal propagation along the geosynchronous orbit. We conclude that the initial compressional perturbations of $\mathrm{Pi} 2$ waves propagate radially and longitudinally as a fast wave in the inner magnetosphere.
\end{abstract}

Keywords: ULF wave; Pi 2 pulsation; Wave propagation; Fast-mode wave; Geosynchronous orbit

\section{Background}

Pi 2 geomagnetic pulsations are defined as impulsive geomagnetic oscillations with a period of 40 to $150 \mathrm{~s}$ (Jacobs et al. 1964). Pi 2 pulsations occur during substorms and other auroral activities such as pseudo breakups and poleward boundary intensifications (Saito 1969; Voronkov et al. 2003; Lyons et al. 1999). Although it is accepted that Pi 2 pulsations (or their source disturbances) are generated in the nightside magnetosphere, their generation and propagation mechanisms have not been determined conclusively.

\footnotetext{
*Correspondence: imajo@kyudai.jp

1 Department of Earth and Planetary Science, Kyushu University, Fukuoka 812-8581, Japan

Full list of author information is available at the end of the article
}

Simultaneous observations in the magnetosphere and on the ground have greatly improved our understanding of low-latitude Pi 2 pulsations. Using data from the geosynchronous ATS-6 satellite and mid-latitude ground stations, (Sakurai and McPherron 1983) found that Pi 2 onsets were almost simultaneous (within $1 \mathrm{~min}$ ). (Yumoto et al. 1989) reported that a magnetic disturbance in the current disruption region (approximately $9 R_{E}$ ) was observed about 1 min earlier than Pi 2 pulsations observed at low-latitude stations. They interpreted the delay time as the travel time of the compressional disturbance. (Takahashi et al. 1995) found that Pi 2 pulsations in the inner magnetosphere had high coherence with $H$ component Pi $2 \mathrm{~s}$ at a low-latitude ground station. The high-coherence Pi 2 s were detected only in the nightside inner magnetosphere $(L \leq 5)$. They suggested that

\section{Springer}

(c) 2014 Imajo et al: licensee Springer. This is an Open Access article distributed under the terms of the Creative Commons Attribution License (http://creativecommons.org/licenses/by/2.0), which permits unrestricted use, distribution, and reproduction in any medium, provided the original work is properly credited. 
low-latitude compressional $\mathrm{Pi} 2$ pulsations (their oscillations appear in the compressional component) had a radial standing structure in the plasmasphere due to a cavity mode resonance (e.g., Sutcliffe and Yumoto 1989; Yeoman and Orr 1989; Nosé 2010). (Takahashi et al. 2003) analyzed electric and magnetic field perturbations of $\mathrm{Pi} 2 \mathrm{~s}$ observed by the Combined Release and Radiation Effects Satellite (CRRES) in the inner magnetosphere. They found the radial standing structure of the fast wave not only inside the plasmasphere but also just outside the plasmasphere. On the other hand, (Kepko and Kivelson 1999) and (Kepko et al. 2001) compared bursty bulk flows (BBFs) (Baumjohann et al. 1990; Angelopoulos et al. 1992) with Pi 2 pulsations at geosynchronous orbit and at ground stations. The waveforms of each compressional Pi 2 wave and earthward BBF were well correlated when the data were shifted by the delay times. These studies argued that low-latitude Pi 2 pulsations are generated by the forced oscillation of $\mathrm{Pi} 2$ periodicities associated with the braking of BBFs. The relationship between BBFs and Pi 2 pulsations was subsequently investigated statistically (Kim et al. 2007; Hsu et al. 2012). Recently, (Murphy et al. 2011) showed an event, where a low-latitude Pi 2 was observed approximately $60 \mathrm{~s}$ earlier than a periodic BBF, and their waveforms were well correlated. They speculated that the fast wave and the BBF were simultaneously launched from the reconnection region, and the fast wave propagated toward Earth faster than the BBF.

Statistical studies of timing relationships have revealed the propagation morphology of ground Pi 2 pulsations. (Uozumi et al. 2000) studied latitudinal propagation characteristics of Pi $2 \mathrm{~s}$ by examining delays of wave packets. They found that the arrival time of $\mathrm{Pi} 2 \mathrm{~s}$ at low-latitude stations are earlier than at a station near the plasmapause and later than at a station in the polar region. (Uozumi et al. 2004) investigated the magnetic local time (MLT) dependences of the delay time of Pi 2 s detected at two pairs of latitudinally and longitudinally separated highlatitude stations. They concluded that the most probable center of azimuthal propagation is $22.5 \mathrm{MLT}$ in the highlatitude region. (Uozumi et al. 2009) showed that the timing of $\mathrm{Pi} 2 \mathrm{~s}$ in the high-latitude region varied with vector components of magnetic data. However, there have only been a few statistical studies investigating the timing of Pi 2 onsets between satellites and ground stations.

Although it is believed that $\mathrm{Pi} 2$ pulsations or their source disturbances propagate as fast-mode waves in the low-latitude magnetosphere, direct evidence of Pi 2 propagation and its morphology have not been statistically established. In this paper, we statistically investigate onset delay times of compressional Pi 2s between the geosynchronous satellite ETS-VIII and the low-latitude ground stations using cross-correlation analyses. We also used a numerical model developed by (Uozumi et al. 2009) to estimate the travel time of the fast-mode wave in the magnetosphere. From both the observations and model estimation, we discuss the propagation of compressional Pi 2 waves in the low-latitude magnetosphere.

\section{Methods}

\section{Analysis procedure}

\section{Data description}

We used the magnetic data from the geosynchronous ETS-VIII satellite and the low-latitude ground observatories. The ETS-VIII was launched on December 18, 2006 and placed in geosynchronous orbit at $146^{\circ} \mathrm{E}$ geographic longitude (Koga and Obara 2008). The projection point of ETS-VIII has been located in the geomagnetic southern hemisphere $\left(\right.$ GMLat. $=-10.8^{\circ}$, GMLon. $\left.=217.5^{\circ}\right)$. The coordinate system of the ETS-VIII magnetic field data is orthogonal, consisting of $P, E$, and $N$ coordinates; $P$ is parallel to the rotational axis, $E$ points radially earthward, and $N$ is azimuthally eastward. We also used ground magnetic data from the low-latitude magnetic data acquisition system (MAGDAS) stations (Yumoto and The MAGDAS Group 2006; Yumoto 2007) and from station Honolulu (HON) operated by the US Geological Survey (USGS). All the data have temporal resolutions of $1 \mathrm{~s}$. The station codes and the coordinates are listed in Table 1. In this study, since we were interested in the compressional component of Pi 2s, we used the $P$ (parallel to the rotational Earth axis) component of the satellite data and the $H$ (geomagnetic northward) component of the ground data to compare the onset timings.

\section{Event selection}

We used $H$-component magnetic data at the ground station Kuju (KUJ) to identify events used in this study. To compare onset timings, we require an undisturbed background before Pi 2 onsets. Therefore, data from KUJ were processed into time-series data of Pi 2 wave energy (Uozumi et al. 2000), defined as an envelope of $\Delta H^{2}(\Delta H$ : filtered $H$ with a range of 40 to $150 \mathrm{~s}$ ) to evaluate the background disturbance and to estimate the maximum energy value and time of each Pi 2 . We defined the background disturbance as the average Pi 2 wave energy 5 to $10 \mathrm{~min}$ before the time of maximum energy. Potential Pi 2 events at KUJ were identified, where the maximum energy was greater than $0.01 n T^{2}$ and the background disturbance was smaller than $10 \%$ of the maximum energy. We further removed events with large noise and other types of disturbances by visual examination. A total of 344 Pi 2 events were selected during the period from December 1 , 2009 to December 1, 2010, at local time of ETS-VIII (LT = $\mathrm{UT}+9.7 \mathrm{~h}$ ) between 19 and $04 \mathrm{LT}$. Of the 344 events, $15 \%$, $48 \%, 27 \%, 6 \%$, and $4 \%$ had $K p$ values of $0,1,2,3$, and 4 , respectively. 
Table 1 Station codes and coordinates of the ground observatories

\begin{tabular}{lccccc}
\hline Station name & Station code & $\begin{array}{c}\text { Geographic } \\
\text { latitude }\end{array}$ & $\begin{array}{c}\text { Geographic } \\
\text { longitude }\end{array}$ & $\begin{array}{c}\text { Geomagnetic } \\
\text { latitude }\end{array}$ & $\begin{array}{c}\text { Geomagnetic } \\
\text { longitude }\end{array}$ \\
\hline Popov Island & PPI & 42.98 & 131.73 & 36.27 & 203.74 \\
Kuju & KUJ & 33.06 & 131.23 & 26.13 & 202.96 \\
Muntinlupa & MUT & 14.37 & 121.02 & 6.79 & 1.56 \\
Yap & YAP & 9.50 & 138.08 & 1.49 & 209.06 \\
Darwin & DAW & -12.41 & 130.92 & -21.91 & 202.81 \\
Learmonth & LMT & -22.22 & 114.10 & -33.59 & 1.24 \\
Townsville & TWV & -19.63 & 146.86 & -28.73 & 1.01 \\
Melbourne & MLB & -38.36 & 145.18 & -49.46 & 220.30 \\
Honolulu & HON & 21.32 & 202.00 & 21.64 & 222.51 \\
Fayum & FYM & 29.18 & 35.50 & 25.76 & 1.16 \\
\hline
\end{tabular}

\section{Calculation of delay times}

To calculate onset delay times, we used a cross-correlation analysis. The calculation procedures were as follows. First, we applied a bandpass filter (filter range set to 40 to $150 \mathrm{~s}$ ). Next, we set a fixed segment of $5 \mathrm{~min}$ from $T_{\max }-120$ $\mathrm{s}$ to $T_{\max }+180 \mathrm{~s}$ in the filtered data, where $T_{\max }$ is the time when the Pi 2 wave energy is maximum. Finally, we calculated a cross-correlation function $(R(\tau))$ for a range of time shifts, $-90 \leq \tau \leq 90 \mathrm{~s}$. We defined $\tau$ when $R(\tau)$ is a maximum peak as a delay time $(\Delta T)$. To avoid analytical errors, the delay time was only used in the analysis when $R(\Delta T)$ was greater than 0.75 , referred to as a 'high-correlation event' in this paper.

\section{Results}

\section{Event examples}

This section provides examples of Pi 2 events. Figure 1a shows the filtered $P$-component data from ETS-VIII and the $H$-component data from the low-latitude ground stations (at 13:20 UT on August 14, 2010), and the satellite and the ground stations around the $135^{\circ} \mathrm{E}$ meridian (except HON and Fayum (FYM)) were in the premidnight sector. The first positive peak of the Pi 2 oscillation at ETS-VIII appeared at 13:19:30 UT (red vertical line), whereas the first simultaneous positive peaks at all the ground stations appeared at 13:20:10 UT (black vertical line). The correlation coefficients and the delay times

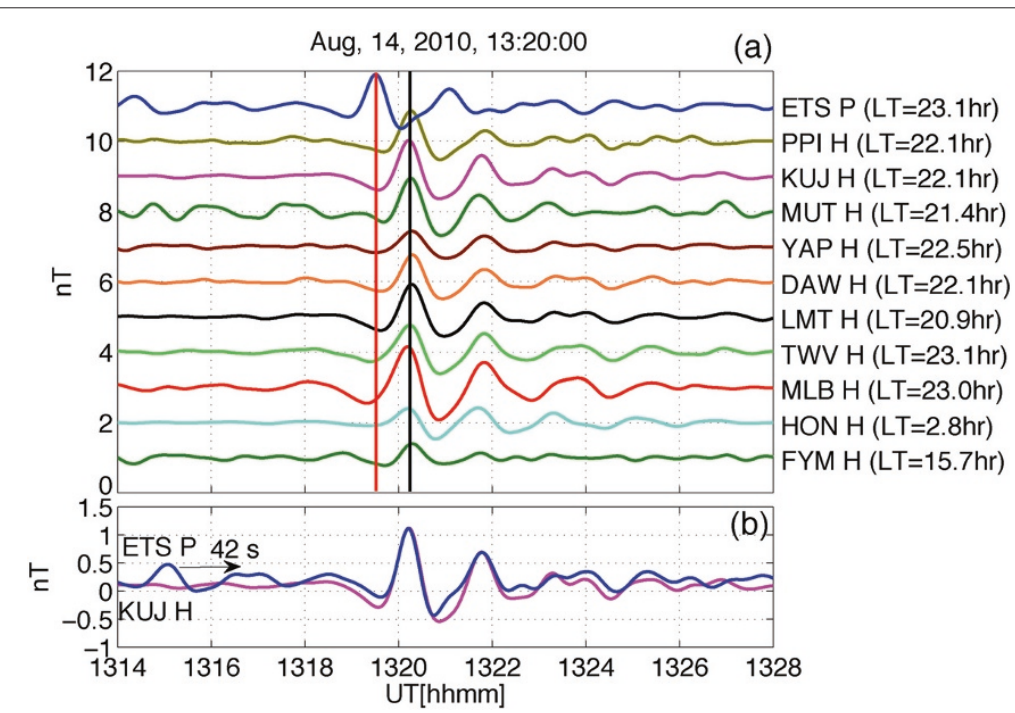

Figure 1 Plots of geomagnetic data around 13:20 UT on August 14, 2010. (a) Filtered P-component data from ETS-VIII (ETS P) and H-component data from low-latitude ground stations around 13:20 UT on August 14, 2010 (filter range of 40 to 150 s). (b) Filtered H-component data from KUJ without a time shift and P-component data from ETS-VIII with a positive time shift of $42 \mathrm{~s}$. 
Table 2 Correlation coefficients and delay times between KUJ and other stations and ETS-VIII

\begin{tabular}{lcr}
\hline Station/satellite & $\boldsymbol{R}(\boldsymbol{\Delta} \boldsymbol{T})$ & $\boldsymbol{\Delta} \boldsymbol{T}$ \\
\hline ETS-VIII & 0.97 & -42 \\
PPI & 0.97 & 4 \\
MUT & 0.95 & 2 \\
YAP & 0.99 & 5 \\
DAW & 0.99 & 5 \\
LMT & 0.99 & 5 \\
TWV & 0.97 & 2 \\
MLB & 0.96 & -1 \\
HON & 0.93 & -4 \\
FYM & 0.88 & -6 \\
\hline APOStivelatime
\end{tabular}

A positive delay time indicates that $\mathrm{Pi} 2 \mathrm{~s}$ were delayed from the $\mathrm{Pi} 2$ at KUJ. between the KUJ data and other stations are shown in Table 2. A positive delay time indicates that a Pi 2 wave was delayed from that of KUJ. As the delay times between KUJ and other ground stations are between -6 and $5 \mathrm{~s}$, the difference between the ground stations is within $11 \mathrm{~s}$. The oscillations on the ground after the onsets are almost inphase. The small onset time delay and phase delay among the nightside low latitudes are consistent with previous studies (Kitamura et al. 1988; Shinohara et al. 1997; Nosé et al. 2006). Figure $1 \mathrm{~b}$ shows the filtered $H$-component at KUJ without a time shift and the $P$-component data at ETS-VIII with a 42-s positive time shift. The onset timings for both Pi 2 s are simultaneous, and the waveforms were well correlated $(R(\Delta T)=0.97)$.

Figure 2 shows the waveform examples of eight highcorrelation events. Each event was observed at different local times. The upper panel of each example shows the non-filtered magnetic variation (without any time shift),

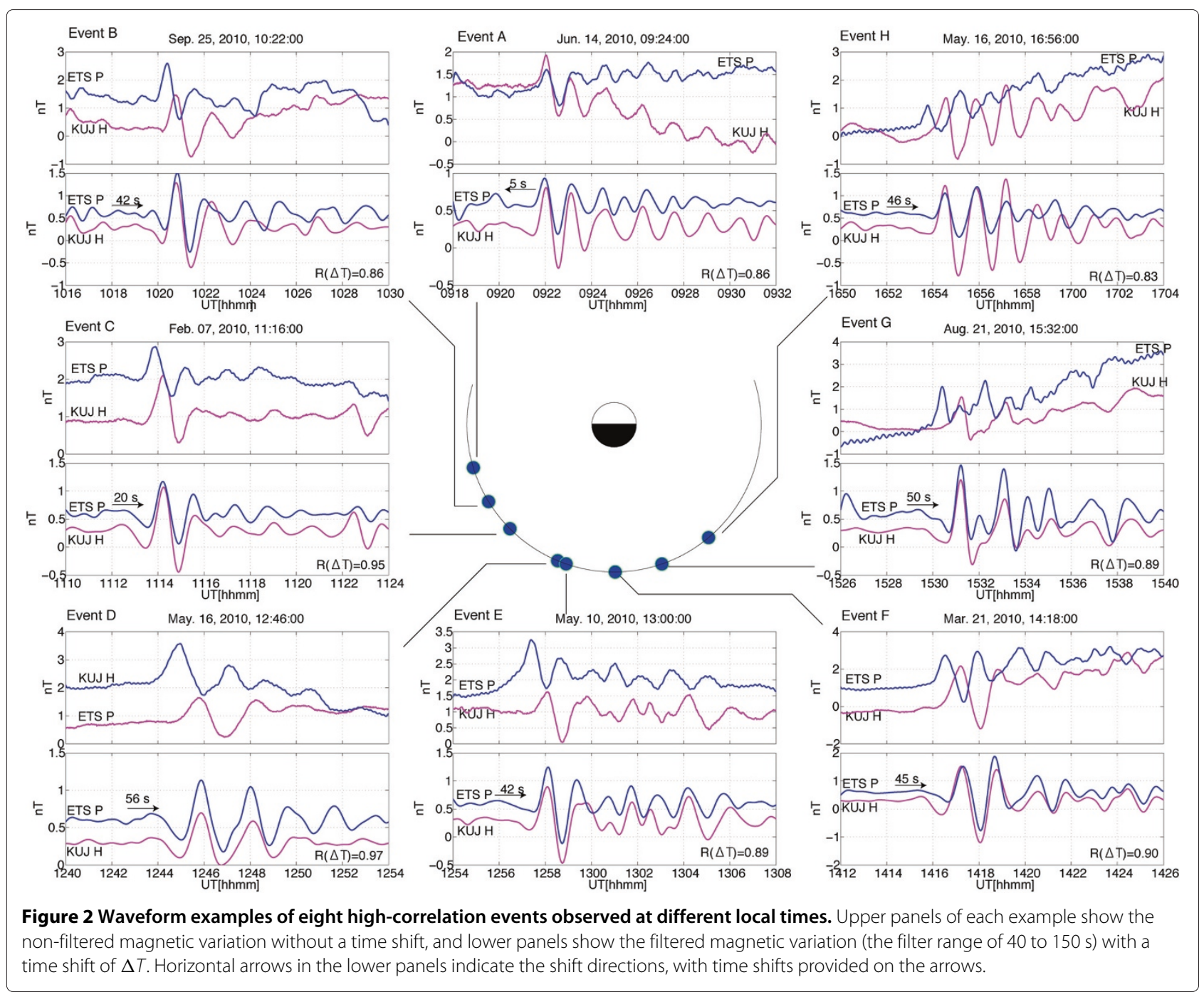


and the lower panels show the filtered magnetic variations (the filter range of 40 to $150 \mathrm{~s}$ ) with a time shift of $\Delta T$. Except for event A, Pi 2s at ETS-VIII start 20 to $56 \mathrm{~s}$ earlier than Pi 2s at KUJ. It is evident from the lower panel (with time shifts) of all the events that Pi 2 waveforms at ETS-VIII and KUJ are well synchronized. The oscillations in the upper panel (without time shifts) of events D, E, and $F$ appear to be out of phase. It should be noted that one cannot identify from a two-point magnetic observation whether these are due to resonance structures of standing waves or propagation delays (this will be discussed later).

\section{Statistical analysis}

We statistically investigated delay times between the $P$-component $\mathrm{Pi} 2 \mathrm{~s}$ at ETS-VIII and the $H$-component Pi $2 \mathrm{~s}$ at KUJ for high-correlation events $(0.75 \leq R(\Delta T))$. As a result of the cross-correlation analyses, 131 events (38\%) have $R(\Delta T)$ values greater than 0.75 . Of the 131 high-correlation events, $24 \%, 54 \%, 18 \%, 4 \%$, and $0 \%$ had $K p$ values of $0,1,2,3$, and 4, respectively. Of the highcorrelation events, $78 \%$ occurred during periods of very low geomagnetic activity $(K p=0,1)$, whereas only $53 \%$ of the low-correlation events $(0.75 \geq R(\Delta T))$ occurred during these periods. Therefore, the high-correlation events tend to occur during low geomagnetic activity.

Figure 3a shows the distribution of local times at ETSVIII $(\mathrm{LT}=\mathrm{UT}+9.7 \mathrm{~h})$ when high-correlation events occurred. Most events occurred between 23 and 24 LT, with more events seen in the premidnight sector than in

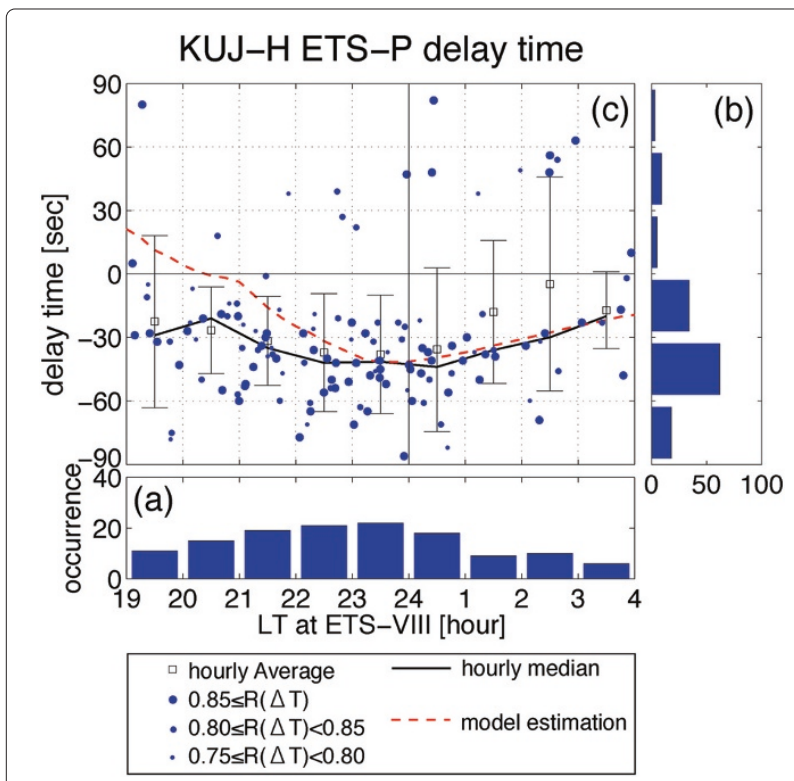

Figure 3 Analysis of 131 high-correlation events. (a) Distribution of local time at ETS-VIII (LT = UT + 9.7 h). (b) Distribution of delay times. (c) Local time dependence of the delay times. the postmidnight sector. Figure 3b shows the distribution of delay times of high-correlation events. The average delay time of all the events was $-29 \mathrm{~s}$ (the median is $-35 \mathrm{~s}$ ), with $87 \%$ of events showing negative delay times that indicate that the Pi 2 pulsations at ETS-VIII occurred before the Pi 2 at KUJ. Figure 3c shows the local time dependence of the delay times between ETS-VIII and KUJ. Because there are some outliers, we show not only the average values and standard deviations but also the median values in each hourly bin. The delay times tend to be longer around the midnight sector than around the dawn and dusk sectors. The dashed red line represents the delay time as a function of the local time calculated by the numerical model of (Uozumi et al. 2009).

\section{Model estimation of fast-wave travel time}

We estimated the fast-wave travel time using the model presented in (Uozumi et al. 2009). This model is based on a three-dimensional magnetohydrodynamic (MHD) propagation model for Pi 2 pulsations developed by (Uozumi et al. 2007) and applied to a realistic plasmapause model which was developed by (Gallagher et al. 2000). The propagation path of MHD waves is based on the mode conversion from fast waves to Alfvén waves (Tamao 1964; Itonaga and Yoshikawa 1996). The Alfvén wave reaching the ground station is excited at the equatorial intersection of the field line by inward fast waves reaching the intersection. We focused on the two-dimensional propagation of the fast waves from a local source in the magnetic equatorial plane.

In this study, the wave source is set at a radial distance of $r=10 R_{E}$ and the longitudinal width of $\mathrm{LT}=22$ to $24 \mathrm{~h}$. (McPherron et al. 2011) have suggested that plasma flows are clustered around 23 LT and likely decelerated at approximately $10 R_{E}$. It is believed that the position of aurora breakups is related to the Pi 2 source (or energy source) (e.g., Kuwashima 1978; Rostoker and Samson 1981). Breakup regions are located around 23 MLT, and their longitudinal width is about 2 MLT on average (Liou et al. 2002). For these reasons, we assumed that the Pi 2 source is not a point source but a longitudinal wide source. We set $K p$ equal to 1 because this is where most of the high-correlation events occurred. $\mathrm{He}^{+}$and $\mathrm{O}^{+}$densities were set to $1 \%$. Figure 4 shows the isochron map of wave fronts of the fast wave in the $X_{\mathrm{GSM}}-Y_{\mathrm{GSM}}$ plane $\left(Z_{\mathrm{GSM}}=0\right)$ estimated from the model. The wave fronts expand anisotropically, depending on the Alfvén velocity distribution. The propagation speed dramatically decreases in the plasmasphere due to the large mass density. In the lower altitude region $\left(r \leq 2 R_{E}\right)$, the speed dramatically increases due to strong magnetic fields. On the ground on the nightside $\left(r=1 R_{E}\right)$, the travel time of the wave front to longitudinally separated points is not significant $(<6 \mathrm{~s})$. 


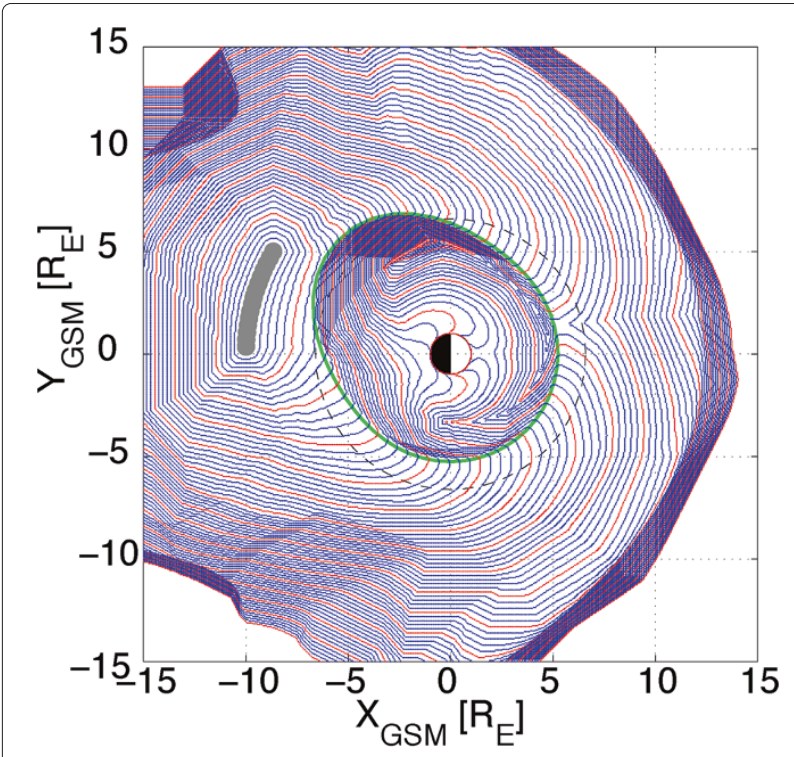

Figure 4 Isochron map showing wave fronts of fast-mode waves illustrated by the model of (Uozumi et al. 2009). The wave source is set at $r=10 R_{E}$ and $L T=22$ to $24 \mathrm{~h}$. Blue and red contours are time intervals of 2 and $10 \mathrm{~s}$, respectively. The dashed circle indicates geosynchronous orbit. The green ellipse illustrates the plasmapause.

The delay time as a function of local time at ETS-VIII calculated by the model of (Uozumi et al. 2009) $\left(\Delta T_{U 09}\right.$ (LT)) is as follows:

$$
\Delta T_{U 09}(\mathrm{LT})=T_{\mathrm{ETS}}(\mathrm{LT})-T_{\mathrm{KUJ}}(\mathrm{LT}),
$$

where $T_{\mathrm{ETS}}(\mathrm{LT})$ and $T_{\mathrm{KUJ}}(\mathrm{LT})$ are the travel time from the source to ETS-VIII and KUJ, respectively, represented by the dashed line in Figure 3c. The minimum peak of $\Delta T_{U 09}$ (LT) appears at $23.5 \mathrm{LT}$ and its value is $-42 \mathrm{~s}$. The value of $\Delta T_{U 09}$ (LT) decreases more notably on the dusk side than on the dawn side.

\section{Discussion}

The observational results show Pi 2 onsets (initial perturbations of Pi 2) propagated from ETS-VIII to the lowlatitude ground stations because in most cases (87\%), Pi 2s at ETS-VIII started before Pi $2 \mathrm{~s}$ at KUJ. Assuming that the location of the Pi 2 source is greater than the geosynchronous altitude, the waves reach the ground through ETS-VIII when the ETS-VIII is in the midnight sector. Therefore, the delay time in the midnight sector is probably equal to the wave travel time from the geosynchronous altitude to the low-latitude ground. The delay time in the midnight sector is calculated to be $-37 \mathrm{~s}$, the average within the 23 to 01 LT. We obtained an average propagation velocity of $920 \mathrm{~km} / \mathrm{s}$. This is in the same order of the typical Alfvén velocity in the inner magnetosphere. In addition, only fast-mode waves can directly propagate across the ambient magnetic field. Thus, we consider that initial perturbations of $\mathrm{Pi} 2 \mathrm{~s}$ propagate as fast-mode waves.

The LT dependence of delay times would be the result of the longitudinal propagation of the fast waves in the magnetosphere. As the isochron map (Figure 4) shows, the arrival times of the fast waves are not very different at each longitudinal ground point, whereas at geosynchronous altitude, the arrival times vary with the local time due to a large longitudinal spatial displacement. When the satellite is located at the magnetospheric flanks, the distance from the source to the satellite becomes longer and comparable to the distance from the source to the ground. In that case, it takes more time for the fast waves to travel from the source to the satellite, and consequently, the difference in the arrival times between the satellite and the ground is smaller. We suggest that the longitudinal propagation at the geosynchronous altitude contributes to the LT dependence of delay times.

Many factors appear to be responsible for the propagation delay of fast waves. The shape of the plasmasphere would be the most important factor. Since the Alfvén velocity dramatically decelerates inside the plasmasphere, the delay time becomes near zero or even positive (earlier at ground stations) when the satellite is inside the plasmasphere. The ratio of heavy ions to proton mass densities is also an important factor. The ratio of $\mathrm{O}^{+}$ions varies depending on geomagnetic activity levels (Lennartsson and Sharp 1982). Because $\mathrm{O}^{+}$ions are about 16 times heavier than $\mathrm{H}^{+}$ions, their contribution to plasma mass density is large, and consequently, the Alfvén velocity can be dramatically altered. Equally important, all components that affect the distribution of magnetic fields and plasma mass densities can be responsible for the delay of the fast waves. To better estimate the source region and the travel time for individual events, more detailed information of the magnetospheric conditions is required.

Propagation of initial Pi 2 perturbations or Pi 2 pulsations themselves involves two scenarios of low-latitude Pi 2 generation, a plasmaspheric resonance, and the BBFdriven mechanism. In the case of the plasmaspheric resonance, an initial Pi 2 perturbation would be a source disturbance triggering the plasmaspheric resonance. This source disturbance has been recognized as the impulsive compressional MHD disturbance (Yumoto et al. 1989; Fujita et al. 2000; Fujita et al. 2002). (Fujita et al. 2000) conducted a simulation of the plasmaspheric virtual resonance (PVR) and showed that the initial perturbation of magnetic fields was delayed between the inside and outside of the plasmasphere. Both observations and simulations of PVR have shown that a phase reversal occurs near the plasmapause. The $74 \%$ of high-correlation events with delay times within half a period of the Pi 2 range (20 to $75 \mathrm{~s}$ ) found in this study implies that onset delays can contribute to phase delays of approximately $180^{\circ}$ between 
geosynchronous altitude and low latitudes. Events D, E, and $\mathrm{F}$ in Figure 2 are good examples showing onset delays that correspond to those phase delays of approximately $180^{\circ}$. On the other hand, Pi $2 \mathrm{~s}$ driven by BBFs are expected to show the characteristics of propagating forced waves. Propagating waves observed at two different points should have high correlation when data are shifted by a propagation delay. Our observations show that there are high-correlation events which have time delays consistent with the fast-wave travel times. Also, there are several events whose waveforms are synchronized, including their irregular features when the data are shifted by the onset delays (for example, Figure $1 \mathrm{~b}$ and events $\mathrm{F}$ and $\mathrm{G}$ in Figure 2). It is plausible that such Pi 2s propagated as a forced fast-mode waves. As stated before, since the delay time corresponds to approximately half the period of Pi 2 pulsations, it is possible that propagation delays contributed to out-of-phase oscillations. However, one cannot conclude from magnetic observation of only two points whether resonance structures of standing waves or propagation delays contribute to these out-of-phase oscillations. Observations by multiple satellites in elliptical orbits (e.g., THEMIS) are potentially useful to reveal the radial structure of propagating delays. The distance from the magnetic equatorial plane to elliptical orbit satellites is variable even if the local time and distance from Earth are the same. Differences in local time and latitude between ground stations and elliptical orbit satellites changes by the hour. Spatial coverage of elliptical orbit satellites is much larger than that of geosynchronous satellites, but the amount of data in each spatial grid is small by necessity. As propagation delay times vary between events, the error relating to a difference in conditions in each case cannot be reduced without enormous data sets.

\section{Conclusion}

We have presented the statistical analysis of onset delay times of compressional Pi 2s which have a high correlation between the low-latitude ground stations and the geosynchronous satellite. The results showed that there were events with quite similar waveforms when the data are shifted by the onset delays. While onset timings at all low-latitude stations were simultaneous, onset timings at the geosynchronous satellite were clearly earlier than at the ground stations. Of the Pi 2s at KUJ, 87\% were delayed from Pi $2 \mathrm{~s}$ at ETS-VIII. The delay time tends to be shorter when the satellite is located at the magnetospheric flanks, which indicates that Pi 2 s (or initial Pi 2 perturbations) propagate longitudinally from the midnight source region. Propagation of initial Pi 2 perturbations or Pi 2 pulsations themselves involves both plasmaspheric resonance and BBF-driven mechanisms. Although we cannot determine whether Pi 2 pulsations themselves are standing waves or propagating waves, we conclude that, in either case, initial perturbations of compressional Pi 2 s propagate as fast waves radially and azimuthally.

\section{Competing interests}

The authors declare that they have no competing interests.

\section{Authors' contributions}

SI analyzed the data and drafted the manuscript. KY conceived of the study and helped interpret the results. TU provided the simulation results of the numerical model. HK helped revise the draft manuscript. SA and Al helped analyze the data. KK, HM, and TO provided the ETS-VIII magnetic data. RM, VAA, AM, and AL made substantial contributions to acquisition of MAGDAS magnetic data. AY made substantial contributions to conception and interpretation of this study. All authors read and approved the final manuscript.

\section{Acknowledgements}

This work was supported by the JSPS Core-to-Core Program, B. Asia-Africa Science Platforms. MAGDAS magnetic data from MUT and YAP are supported by Mr. Commodore Romeo I. Ho and Dr. David Aranug, respectively. The Honolulu magnetic field data were provided by the USGS Geomagnetism Program. Kp-index data was provided by the World Data Center for Geomagnetism, Kyoto, Website. Financial support was provided by the Ministry of Education, Science and Culture of Japan in the form of Grants-in-Aid for Overseas Scientific Survey (18253005 and 22253007).

\section{Author details}

${ }^{1}$ Department of Earth and Planetary Science, Kyushu University, Fukuoka 812-8581, Japan. ${ }^{2}$ International Center for Space Weather Science and Education, Kyushu University, Fukuoka 812-8581, Japan. ${ }^{3}$ Department of Liberal Arts and Sciences, Kagoshima National College of Technology, Kagoshima 899-5193, Japan. ${ }^{4}$ Japan Aerospace Exploration Agency, Tsukuba 305-8505, Japan. ${ }^{5}$ Planetary Plasma and Atmospheric Research Center, Graduate School of Science, Tohoku University, Sendai 980-8578, Japan. ${ }^{6}$ IPS Radio and Space Services, Bureau of Meteorology, Sydney, New South Wales 1240, Australia. ${ }^{7}$ Pacific Oceanological Institute, FEB RAS, Vladivostok 690041, Russia. ${ }^{8}$ Physics Department, Helwan University, Ain Helwan 11795, Egypt. ${ }^{9} \mathrm{CSIRO}$ Darwin Laboratory, Darwin 0828, Australia.

Received: 9 October 2013 Accepted: 9 April 2014

Published: 24 April 2014

\section{References}

Angelopoulos V, Baumjohann W, Kennel CF, Coroniti FV, Kivelson MG, Pellat R, Walker RJ, Lühr H, Paschmann G (1992) Bursty bulk flows in the inner central plasma sheet. J Geophys Res 97(A4): 4027-4039. doi:10.1029/91JA02701

Baumjohann W, Paschmann G, Lühr H (1990) Characteristics of high-speed ion flows in the plasma sheet. J Geophys Res 95(A4): 3801-3809. doi:10.1029/JA095iA04p03801

Fujita S, Itonaga M, Nakata H (2000) Relation between the Pi2 pulsations and the localized impulsive current associated with the current disruption in the magnetosphere. Earth Planets Space 52: 267-281

Fujita S, Nakata H, Itonaga M, Yoshikawa A, Mizuta T (2002) A numerical simulation of the Pi2 pulsations associated with the substorm current wedge. J Geophys Res 107(A3): 1034. doi:10.1029/2001JA900137

Gallagher DL, Craven PD, Comfort RH (2000) Global core plasma model. J Geophys Res 105(A8): 18819-18833. doi:10.1029/1999JA000241

Hsu TS, McPherron RL, Angelopoulos V, Ge Y, Zhang H, Russell C, Chu X, Kissinger J (2012) A statistical analysis of the association between fast plasma flows and Pi2 pulsations. J Geophys Res 117: A11221. doi:10.1029/2012JA018173

Itonaga M, Yoshikawa A (1996) The excitation of shear Alfvén wave and the associated modulation of compressional wave in the inner magnetosphere. J Geomagn Geoelectr 48: 1451

Jacobs JA, Kato Y, Matsushita S, Troitskaya VA (1964) Classification of geomagnetic micropulsations. J Geophys Res 69(1): 180-181. doi:10.1029/JZ069i001p00180

Kepko L, Kivelson MG (1999) Generation of Pi2 pulsations by bursty bulk flows. J Geophys Res 104(A11): 25021-25034. doi:10.1029/1999JA900361

Kepko L, Kivelson MG, Yumoto K (2001) Flow bursts, braking, and Pi2 pulsations. J Geophys Res 106(A2): 1903-1915. doi:10.1029/2000JA000158 
Kim KH, Takahashi K, Ohtani S, Sung SK (2007) Statistical analysis of the relationship between earthward flow bursts in the magnetotail and low-latitude Pi2 pulsations. J Geophys Res 112: A10211. doi:10.1029/2007JA012521

Kitamura T, Saka O, Shimoizumi M, Tachihara H, Oguti T, Araki T, Sato N, Ishitsuka M, Veliz O, Nyobe JB (1988) Global mode of Pi2 waves in the equatorial region: difference of $\mathrm{Pi} 2$ mode between high and equatorial latitudes. J Geomagn Geoelectr 40: 621-634

Koga K, Obara T (2008) Development and measurement result of technical data acquisition equipment (TEDA) on board ETS-VIII. IEICE Tech Rep SANE 2008-2017: 23-25

Kuwashima M (1978) Wave characteristics of magnetic Pi 2 pulsations in the auroral region-spectral and polarization studies. Mem Natl Inst Polar Res Ser A 15: 37

Lennartsson W, Sharp RD (1982) A comparison of the 0.1-17 keV/e ion composition in the near equatorial magnetosphere between quiet and disturbed conditions. J Geophys Res 87(A8): 6109-6120. doi:10.1029/JA087iA08p06109

Liou K, Meng Cl, Lui ATY, Newell PT, Wing S (2002) Magnetic dipolarization with substorm expansion onset. J Geophys Res 107: 1131. doi:10.1029/2001JA000179

Lyons LR, Nagai T, Blanchard GT, Samson JC, Yamamoto T, Mukai T, Nishida A, Kokubun S (1999) Association between Geotail plasma flows and auroral poleward boundary intensifications observed by CANOPUS photometers. J Geophys Res 104: 4485. doi:10.1029/1998JA900140

McPherron RL, Hsu TS, Kissinger J, Chu X, Angelopoulos V (2011) Characteristics of plasma flows at the inner edge of the plasma sheet. J Geophys Res 116: A00133. doi:10.1029/2010JA015923

Murphy KR, Rae IJ, Mann IR, Walsh AP, Milling AP, Kale A (2011) The dependence of Pi2 waveforms on periodic velocity enhancements within bursty bulk flows. Ann Geophys 29: 493-509. doi:10.5194/angeo-29-493-2011

Nosé M (2010) Excitation mechanism of low-latitude Pi2 pulsations: cavity mode resonance or BBF-driven process. J Geophys Res 115: A07221. doi:10.1029/2009JA015205

Nosé M, Liou K, Sutcliffe PR (2006) Longitudinal dependence of characteristics of low-latitude Pi2 pulsations observed at Kakioka and Hermanus. Earth Planets Space 58: 775-783

Rostoker G, Samson JC (1981) Polarization characteristics of Pi 2 pulsations and implications for their source mechanisms: location of source regions with respect to the auroral electrojets. Planet Space Sci 29: 225. doi:10.1016/0032-0633(81)90036-2

Saito T (1969) Geomagnetic pulsations. Space Sci Rev 10: 319-412. doi:10.1007/BF00203620

Sakurai T, McPherron RL (1983) Satellite observations of Pi2 activity at synchronous orbit. J Geophys Res 88: 7015-7027. doi:10.1029/JA088iA09p07015

Shinohara M, Yumoto K, Yoshikawa A, Saka O, Solovyev SI, Vershinin EF, Trivedi NB, Da Costa JM (1997) The 210 MM Magnetic Observation Group. Wave characteristics of daytime and nighttime Pi 2 pulsations at the equatorial and low latitudes. J Geophys Res 24(18): 2279-2282. doi:10.1029/97GL02146

Sutcliffe PR, Yumoto K (1989) Dayside Pi2 pulsations at low latitudes. Geophys Res Rett 16(8): 887-890. doi:10.1029/GL016i008p00887

Takahashi K, Ohtani S, Anderson BJ (1995) Statistical analysis of Pi 2 pulsations observed by the AMPTE CCE spacecraft in the inner magnetosphere. J Geophys Res 100(A11): 21929-21941. doi:10.1029/95JA01849

Takahashi K, Lee DH, Nosé M, Anderson RR, Hughes WJ (2003) CRRES electric field study of the radial mode structure of Pi 2 pulsations. J Geophys Res 108(A5): 1210. doi:10.1029/2002JA009761

Tamao T (1964) The structure of three-dimensional hydromagnetic waves in a uniform cold plasma. J Geomagn Geoelectr 18: 89

Uozumi T, Yumoto K, Kawano H, Yoshikawa A, Olson JV, Solovyev SI, Vershinin EF (2000) Characteristics of energy transfer of Pi 2 magnetic pulsations: latitudinal dependence. Geophys Res Rett 27(11): 1619-1622. doi:10.1029/1999GL010767

Uozumi T, Yumoto K, Kawano H, Yoshikawa A, Ohtani S, Olson JV, Akasofu SI, Solovyev SI, Vershinin EF, Liou K, Meng CI (2004) Propagation characteristics of Pi 2 magnetic pulsations observed at ground high-latitudes. J Geophys Res 109: A08203. doi:10.1029/2003JA009898
Uozumi T, Kawano H, Yoshikawa A, Itonaga M, Yumoto K (2007) Pi2 source region in the magnetosphere deduced from CPMN data. Planet Space SC 55: 849-857. doi:10.1016/j.pss.2006.03.016

Uozumi T, Abe S, Kitamura K, Tokunaga T, Yoshikawa A, Kawano H, Marshall R, Morris RJ, Shevtsov BM, Solovyev SI, McNamara DJ, Liou K, Ohtani S, Itonaga M, Yumoto K (2009) Propagation characteristics of $\mathrm{Pi} 2$ pulsations observed at high- and low-latitude MAGDAS/CPMN stations: a statistical study. J Geophys Res 114: A11207. doi:10.1029/2009JA014163

Voronkov IO, Donovan EF, Samson JC (2003) Observations of the phases of the substorm. J Geophys Res 108: 1073. doi:10.1029/2002JA009314

Yeoman TK, Orr D (1989) Phase and spectral power of mid-latitude Pi2 pulsations: evidence for a plasmaspheric cavity resonance. Planet and Space Sci 96(A6): 9811-9813. doi:10.1016/0032-0633(89)90107-4

Yumoto K, The MAGDAS Group (2006) MAGDAS project and its application for space weather. In: Gopalswamy N, Bhattacharya A (eds) Solar influence on the heliosphere and Earth's environment: recent progress and prospects. Quest Publications, Wheaton, pp 309-405

Yumoto K (2007) The MAGDAS Group. Space weather activities at SERC for IHY: MAGDAS. Bull Astr Soc India 35: 511-522

Yumoto K, Takahashi K, Saito T, Menk FW, Fraser BJ, Potemra TA, Zanetti LJ (1989) Some aspects of the relation between Pi 1-2 magnetic pulsations observed at $L=1.3-2.1$ on the ground and substorm-associated magnetic field variations in the near-earth magnetotail observed by AMPTE CCE. J Geophys Res 94(A4): 3611-3618. doi:10.1029/JA094iA04p03611

doi:10.1186/1880-5981-66-20

Cite this article as: Imajo et al:: Analysis of propagation delays of compressional Pi 2 waves between geosynchronous altitude and low latitudes. Earth, Planets and Space 2014 66:20.

\section{Submit your manuscript to a SpringerOpen ${ }^{\circ}$ journal and benefit from:}

- Convenient online submission

- Rigorous peer review

- Immediate publication on acceptance

- Open access: articles freely available online

- High visibility within the field

- Retaining the copyright to your article

Submit your next manuscript at springeropen.com 